\title{
Mechanisms and Targets Involved in Dissemination of Ovarian Cancer
}

\author{
ULRICH H. WEIDLE ${ }^{1}$, FABIAN BIRZELE ${ }^{2}$, GWENDLYN KOLLMORGEN $^{1}$ and RÜDIGER RUEGER ${ }^{1}$ \\ ${ }^{1}$ Roche Innovation Center Munich, Roche Diagnostics GmbH, Penzberg, Germany; \\ ${ }^{2}$ Roche Innovation Center Basel, F. Hoffmann-LaRoche Ltd., Basel, Switzerland
}

\begin{abstract}
Ovarian carcinoma is associated with the highest death rate of all gynecological tumors. On one hand, its aggressiveness is based on the rapid dissemination of ovarian cancer cells to the peritoneum, the omentum, and organs located in the peritoneal cavity, and on the other hand, on the rapid development of resistance to chemotherapeutic agents. In this review, we focus on the metastatic process of ovarian cancer, which involves dissemination of, homing to and growth of tumor cells in distant organs, and describe promising molecular targets for possible therapeutic intervention. We provide an outline of the interaction of ovarian cancer cells with the microenvironment such as mesothelial cells, adipocytes, fibroblasts, endothelial cells, and other stromal components in the context of approaches for therapeutic interference with dissemination. The targets described in this review are discussed with respect to their validity as drivers of metastasis and to the availability of suitable efficient agents for their blockage, such as small molecules, monoclonal antibodies or antibody conjugates as emerging tools to manage this disease.
\end{abstract}

Ovarian cancer is a deadly disease due to its rapid and early metastasis to the peritoneum, so-called transcoelomic dissemination. This rapid spread is facilitated by ascitic fluid, which embeds the primary tumor and acts as a medium to promote dissemination to the peritoneum and the omentum, as well as to organs within the peritoneal cavity. In addition to this physical prerequisite, which allows angiogenesis-

Correspondence to: Rüdiger Rüger, Roche Innovation Center, Im Nonnenwald 2, D-82372 Penzberg, Germany. Tel: +49 8856602022 , e-mail: ruediger.rueger@ roche.com

Key Words: Adipocytes, ascites, epithelial ovarian cancer Penzberg, EOC, homing, mesothelial cells, growth of metastases, peritoneal cells, therapeutic targets, transcoelomic dissemination, review. independent dissemination, other more common mechanisms of successful metastasis, such as interaction of the tumor cells with fibroblasts, endothelial cells, mesothelial cells, adipocytes, platelets, and immune cells are also essential for the spread of ovarian carcinoma (1). The high lethality of ovarian carcinoma is caused by the inability to detect the disease at an early, organ-confined state; $70 \%$ of patients initially present with disease that has spread beyond the ovaries (2). Organ-confined low-grade tumors can be removed by surgery without subsequent chemotherapy, while advanced disease is often treated with debulking surgery, followed by chemotherapy with carboplatin and paclitaxel (3). Almost all patients with advanced disease experience relapse due to chemoresistance and only $30 \%$ of them survive as long as 5 years after initial diagnosis (3).

Ovarian carcinomas display some features that seem to prevent the success of chemotherapy. Firstly, growth factors of the tumor microenvironment support the stabilization of $\mathrm{X}$ chromosome-linked inhibitor of apoptosis (XIAP), an antiapoptotic protein inhibiting caspases 3 and 7, which has been shown to mediate chemoresistance (4-6). Secondly, ovarian carcinomas exhibit intratumoral heterogeneity as is often the case with malignancies (7). More specifically, phylogenetic analysis of ovarian carcinomas from different patients revealed marked differences in the degree of clonal expression of genes, as well as subclonal chemotherapyresistant populations based on the expression of chemoresistance-conferring genes (8). Lastly, chemotherapyresistant tumor cells derived from ascites of patients with ovarian cancer are highly tumorigenic in mice and often exhibit stem cell-like characteristics (9).

In addition to intratumoral heterogeneity, different subtypes of ovarian carcinoma have been identified. More than $90 \%$ of ovarian carcinomas have an epithelial histology with the following subtypes: serous, mucinous, endometrioid, clear cell, transitional, squamous, mixed, and undifferentiated or unclassifiable (10). Among these, serous epithelial ovarian 
cancer (EOC) is the most common, accounting for $90 \%$ of ovarian cancer cases. (11). Serous EOCs are classified into high- and low-grade subtypes according to the degree of differentiation and specific genetic profile (12). High-grade serous EOCs account for $70 \%$ of all ovarian cancer cases. Tumor cells from this group exhibit stem cell-like characteristics, as well as de-activating mutations in tumor suppressor genes p53 and breast cancer antigens 1 and 2 (BRCAl and -2) as well as loss of heterozygosity ( $\mathrm{LOH}$ ) on chromosomes $7 q$ and $9 q$ (13). In contrast, low-grade serous EOCs exhibit a different distinct genetic profile, including oncogene-activating mutations in Kirsten rat viral oncogene homolog $(K R A S)$, v-raf murine sarcoma viral oncogene homolog B1 (BRAF), and phosphoinositide-3-kinase-catalytic $\alpha$ (PIK3CA), as well as $\mathrm{LOH}$ on chromosome $\mathrm{Xq}$, microsatellite instability, and expression of amphiregulin (14).

In this review, we focus on high-grade serous EOCs and their typical transcoelomic mode of metastasis. In addition to the above-mentioned genetic profile of de-activated tumorsuppressor genes, more recent further genetic classification has revealed additional targets that may possibly be suitable for anti-metastatic treatment of aggressive high-grade serous EOCs. The targets are discussed and analyzed with respect to their validity as contributors to metastasis. Their usefulness regarding blockage or elimination using small molecules, monoclonal antibodies or antibody conjugates in preclinical models and clinical studies is outlined and discussed with respect to new concepts for treatment of metastatic ovarian carcinoma. We do not discuss treatment modalities based on inherited or sporadic mutations in ovarian cancer cells which result in chemosensitization or synthetic lethality since these mutations are not specific hallmarks of disseminated ovarian carcinoma.

\section{General Issues of Pathogenesis of Ovarian Cancer}

Three possible anatomical locations for the origin of ovarian carcinoma have been suggested: the ovarian surface epithelium (OSE), the mesothelium covering the peritoneal cavity, and the fallopian tube epithelium (15). Among these, the OSE seems to be the most common site (2). For the mechanism of ovarian carcinoma tumorigenesis, three hypotheses have been raised (2). The first hypothesis claims this is the result of an accumulation of genetic changes caused by the repetitive wounding of the OSE and postovulatory repair after each ovulation process (2). The second hypothesis postulates that pituitary gonadotropins act as mitogens or even as carcinogens at persistently high concentrations that are detectable after menopause (2). The third hypothesis implies inflammation as the cause of ovarian carcinoma. In this case inflammation may result from exposure of OSE to pro-inflammatory cytokines/chemokines, as well as to matrix-remodeling enzymes generated at the site of ovulation. With respect to the genesis of ovarian carcinoma, a puzzling issue needs to be resolved: Ovarian carcinoma is detected bilaterally in $57.5 \%$ of cases (16). Whether bilaterality represents two primary tumors or is a consequence of collateral metastasis is unknown.

Irrespective of the exact course of pathogenesis of ovarian cancer as discussed above, it is generally accepted that metastasis of serous EOC can occur via the transcoelomic, hematogenous or lymphatic route (10). In this review, we focus on the mechanisms that are related to the transcoelomic route of dissemination, the most frequently observed mechanism of metastasis of this type of cancer $(17,18)$. Hematological metastasis in ovarian cancer is rare, despite the presence of circulating tumor cells after initial diagnosis (19). This fact is supported by findings from the application of the peritoneous shunting technique (20) used to alleviate the pain of patients with terminal ovarian cancer by reducing the volume of ascites in the peritoneum. This technique creates anastomosis between the peritoneum and the jugular vein. Continuous entry of millions of tumor cells derived from malignant ascites into the bloodstream can be detected, but the shunts were not found to significantly increase the risk of metastasis to organs outside the peritoneal cavity (20). These findings are a compelling verification of the 'seed and soil' hypothesis (21), which claims compatibility of colonization with the corresponding target tissues. Recently, this currently held assumption of nonhematogenous spread of ovarian cancer metastasis was challenged by employing a parabiosis model in which two living mice were joined together to develop a shared circulatory system (22). In this model, preferential metastasis of ovarian cancer to the omentum was mediated by the interaction between human epidermal growth factor receptor 3 (HER3) expressed on ovarian cancer cells and its ligand neuregulin 1 (NRG1) expressed by cells in the omentum, allowing tumor homing to as well as growth in the omentum (22). Ovarian cancer cells can also spread via ovary-draining lymphatics to pelvic and para-aortic lymph nodes, but this mode of dissemination is rare.

The role of genetic changes as drivers of metastasis of ovarian carcinoma is an unresolved issue. Investigations of the transcriptional profile by microchip analysis $(23,24)$, chromosomal constitution after genomic hybridization (25, 26), and parsimony tree analysis (27) of paired ovarian carcinomas and their corresponding metastases concluded that tumor cells from both locations exhibited the same pattern of expression. These findings are in agreement with the hypothesis that ovarian cancer metastases are generated by passive transport of tumor cells with ascites. In contrast, primary ovarian cancer can also carry complex karyotypic changes, while metastases thereof possessed either normal genomes or even fewer genetic abnormalities (28). This would suggest that secondary peritoneal implants are de novo occurrences in carcinogenesis of ovarian carcinoma. 


\section{Transcoelomic Metastasis of Ovarian Carcinoma}

This is a multistep process involving dissociation, homing, and growth of tumor cells in distant organs. The process is triggered by complex interactions of the tumor cells with the microenvironment and induction of diverse pathways (29-31). Crucial steps involve shedding of tumor cells from the primary tumor, development of resistance to anoikis, formation of multicellular aggregates (spheroids), transport by peritoneal fluid, implantation into the peritoneum by formation of mesothelial lining of pelvic and abdominal organs such as uterus and fallopian tubes, the omentum and the mesentery, and their growth as nodules $(10,32)$. Dissociation of tumor cells from the OSE is associated with epithelial-mesenchymal transition (EMT) (33). Once established in the omentum, an epithelial phenotype is recovered by mesenchymal-epithelial transition (34). Shed tumor cells are transported by peritoneal fluid and seed the peritoneal cavity with tumor cells, which is associated with the formation of ascites (35). Ascitic fluid is rich in factors which promote tumor cell growth and invasion, such as matrix metalloproteinases (MMPs), urokinase-type plasminogen activator (uPA), lysophosphatic acid, CXC chemokine ligand 12 (CXCL12), and the ligand of transmembrane tyrosine kinase c-MET proto-oncogene product (c-MET), hepatocyte growth factor (HGF) (36).

Formation of spheroids is another characteristic feature of ovarian cancer metastasis (37). Spheroids provide an evolutionary advantage in tumor progression as they are less sensitive to chemotherapy due to up-regulation of B-cell leukemia-xL (BCL-xL) (38). In addition, they exhibit pronounced capacity to adhere to components of the ECM and mesothelial cells (37). Tumor cells in spheroids are also protected against antitumoral immune effector cells $(29,30)$. Interactions of disseminated individual tumor cells or tumor cell spheroids with cells of the microenvironment, such as endothelial cells, platelets, immune cells, fibroblasts, adipocytes, or mesenterial cells, are essential for metastasis of ovarian cancer at different stages of the metastatic process (1). Interaction of ovarian tumor cells with stromal cells promotes metastatic progression. For example, crosstalk of tumor cells with cancer-associated fibroblasts results in expression of invasion-promoting enzymes (30). Interaction with mesenteric cells is essential for implantation in the peritoneum (18). Adipocytes of the omentum are promoters of ovarian cancer metastasis by providing energy for growth of disseminated ovarian cancer cells (39). Endothelial cells are of importance for the metastatic process, as they promote the growth of metastases. After adherence, tumor cells penetrate the mesothelium and subsequently invade the underlying tissue, where they are able to induce angiogenesis as a prerequisite for growth and proliferation of tumor nodules (29-31). Crosstalk with immune cells by inactivation of immune effector cells through regulatory T-cells and due to other immunosuppressive mechanisms is another issue (29, 30). Tumor-associated macrophages have been identified as important contributors to metastasis, based on their shift from an antitumoral (M1) to a pro-tumoral (M2) subtype in ovarian cancer $(40,41)$. It has also been shown that platelets can interact with ovarian cancer cells, resulting in activation of pathways which mediate induction of EMT, extravasation, invasion, and metastasis (42-44). The contents released from activated platelets into the peritumoral space can induce tumor cell proliferation and extravasation of ovarian cancer cells (42). The role of exosomes in ovarian cancer dissemination is under intensive investigation (45-47). Exosomes from SKOV-3 and OVCAR-3 ovarian cancer cells can induce differentiation of adipose tissue-derived stem cells into tumor growth- and invasion-promoting myofibroblasts, which secrete activated immunosuppressive transforming growth factor $\beta$ (TGF $\beta$ ) (48).

In the following, we describe targets involved in dissemination, homing, and metastatic growth of ovarian carcinoma cells. They can be grouped into target classes, namely proteases, components of the ECM, adhesion and signaling molecules, metabolism-related targets, chemokines, and finally pro-angiogenic factors and their corresponding receptors. An overview of the targets discussed in this review is shown in Figure 1. An exclusive assignment to metastatic events such as dissociation, homing, and growth is not possible for all targets, since some of them have overlapping functions at different stages of the metastatic process. All targets discussed in the following are related to serous EOC.

\section{Possible Targets for Therapeutic Intervention}

Proteases and components of the ECM. Proteases are involved in tumor progression, as well as dissemination and metastatic homing of ovarian cancer cells. Increased expression of proteases is associated with the progression from benign to advanced ovarian cancer (49). Functionally, proteases were originally implicated in the early stages of ovarian cancer metastasis as they are able to cleave components of the ECM (50). Recently, the complex and possibly more important role of proteases in the metastatic process comprises their ability to modulate important factors such as cell adhesion molecules, growth factors, and their receptors, thereby conditioning the microenvironment in some defined instances in a pro-metastatic way (51). The role of proteases in modulating metastasis-specific proteins/targets in ovarian carcinoma is discussed in conjunction with the specific targets. We describe the role of the matrix metalloproteinases (MMPs) MT-MMP1 and MMP7 in shedding of mucin 16 (MUC16) and E-cadherin or cleavage of vitronectin and fibronectin, respectively, and of integrin $\alpha 6 \beta 1$ in the regulation of ECM degradation by the serine 


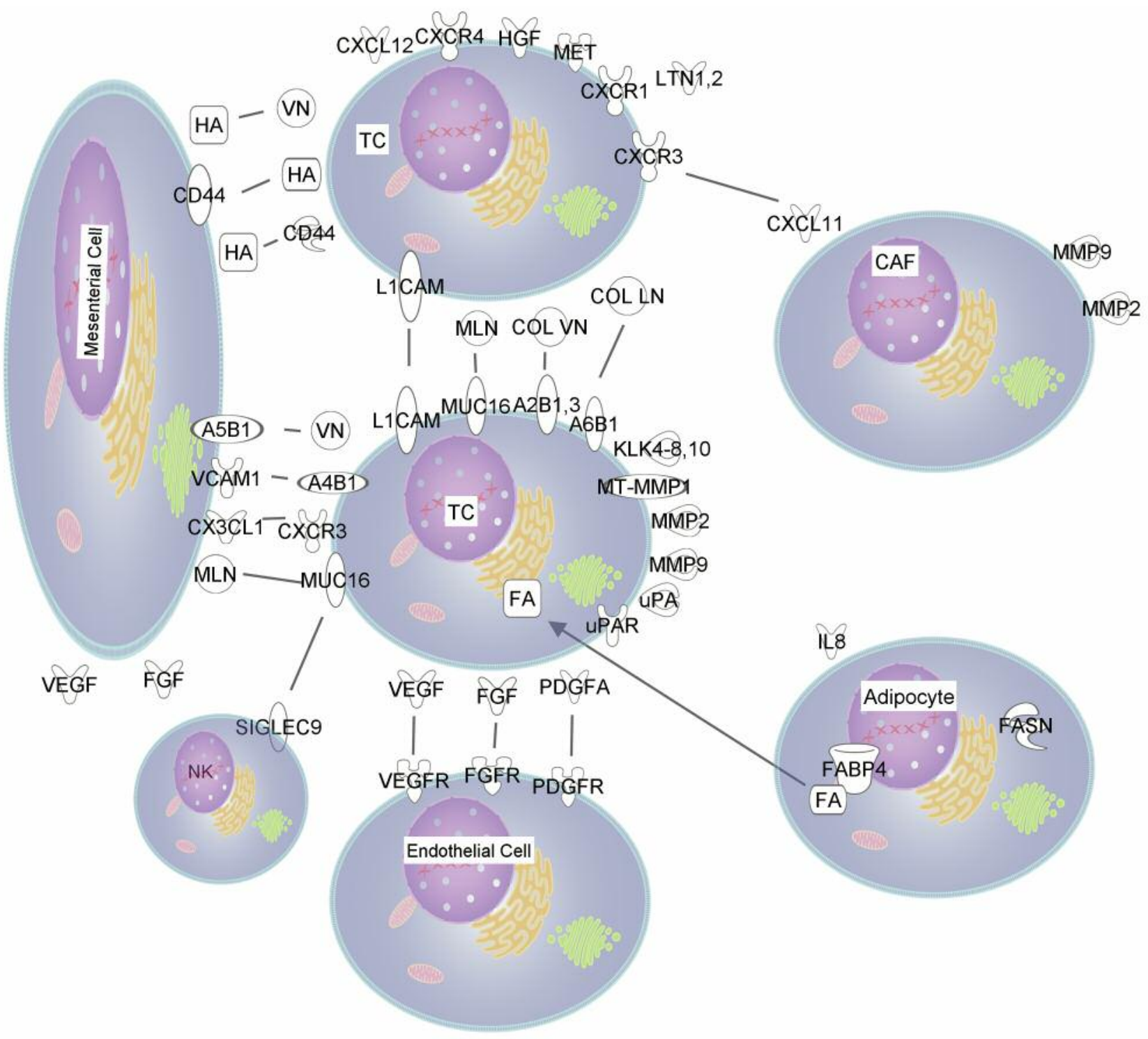

Figure 1. Overview of targets involved in metastasis of ovarian cancer. Targets discussed in this review are shown. The inner circle represents an ovarian cancer cell and we highlight intracellular, transmembrane and glycophosphatidylinositol-anchored targets as well as ligands expressed by stromal cells or ovarian cancer cells as outer circles. The stromal ligands can be expressed by adipocytes, cancer-associated fibroblasts (CAF), endothelial cells, mesenterial cells or natural killer (NK) cells. A2B1, A3B1, A4B1, A5B1, A6B1: Integrins $\alpha 2 \beta 1, \alpha 3 \beta 1, \alpha 4 \beta 1, \alpha 5 \beta 1, \alpha 6 \beta 1 ; C D 44$ : cluster of differentiation 44; COL: collagen type IV; CX3CL1: C-X3-C motif ligand 1; CX3CR1: CX3C chemokine receptor 1; CXCL 11,12: CXC chemokine ligand 11,12; CXCR 3,4: CXC chemokine receptor 1,3, 4; FABP4: fatty-acid binding protein 4; FAS: fatty acid synthase; FGF: fibroblast growth factor; FGFR: FGF receptor; FN: fibronectin; HA: hyaluronic acid; HGF: hepatocyte growth factor; IL8: interleukin 8; KLK4-8, 10: kallikreins 4-8, 10; L1CAM: L1 cell adhesion molecule; LN: laminin; LTN: lymphotactin; MMP2/9: matrix metalloproteinase 2 or 9; MT-MMP1: membrane-type matrix metalloproteinase 1; MET: receptor tyrosine kinase 1; MLN: mesothelin; MUC16: mucin 16; PDGF-A: placental growth factor isoform A; PDGFR: PDGF receptor; SIGLEC 9: sialic acid recognizing immunoglobulin superfamily lectin 9; uPA: urokinase-type plasminogen activator; uPAR: urokinase plasminogen activator receptor; VCAM1: vascular cell adhesion molecule 1; VEGF: vascular endothelial growth factor; VEGFR: VEGF receptor; vitronectin: vitronectin; XCR1: lymphotactin receptor X chemokine receptor 1 .

protease plasminogen. Likewise, induction of protease expression by some of these targets is discussed, for example the induction of MMP2 and MMP9 by L1-cell adhesion molecule (L1CAM), lysophosphatic acid and c-MET, as well as their expression in the tumor microenvironment. The role of interaction of the serine protease UPA with its receptor uPAR in metastasis of ovarian cancer was validated in mouse xenograft models of ovarian cancer. Dissemination was 
inhibited by antisense RNA directed against uPA (52), as well as by expression of a recombinant extracellular domain of the uPAR as a scavenger for uPA (53).

Proteases and their corresponding substrates are expressed in many types of tissues under normal physiological conditions. Their value as targets for treatment of dissemination of ovarian carcinoma is rather doubtful as they are involved in a multitude of physiological and pathophysiological functions and often cannot be perceived of as being clearly pro- or anti-tumoral, which was one of the reasons why clinical studies with MMP were likely to fail in patients with cancer.

Kallikreins (KLKs) are a family of 15 serine proteases which are expressed in diverse tissues and are aberrantly expressed in EOC (54). Gene microarray analysis and protein quantitation revealed up-regulation of KLKs 4-8 and KLK10 in EOC (55-59). KLKs contribute to ovarian cancer dissemination at different levels such as ECM cleavage, cell shedding, and spheroid formation (54). KLKs 4-7 regulate the breakdown of ECM proteins such as fibronectin, vitronectin and laminin, as well as type I and IV collagen, which can favor pro-metastatic conditions in the microenvironment of the tumor (54). KLK4 can proteolytically activate uPA from pro-uPA but also cleave its receptor uPAR, both known to be present at elevated levels in the ascites of patients with EOC. The consequences can be pro-metastatic due to activation of uPA, as well as anti-metastatic due to inhibition of uPA/uPAR-mediated conversion of plasminogen to plasmin by cleavage of uPAR (60). Another important function of KLKs is their involvement in the formation of tumor spheroids (54). These multicellular structures were shown to efficiently support survival of disseminating ovarian carcinoma cells (61). They are able to invade peritoneal cell layers and form distant metastatic foci (62). KLK4 can promote spheroid formation leading to homotypic cell adhesion, as shown with KLK4-expressing SKOV3 cells and with SKOV3 cells treated with recombinant active KLK4 (54). Although the mechanisms of this phenomenon are not yet resolved, increased adhesion of tumor cells to ECM proteins fibronectin or vitronectin or cell-ECM interaction via $\alpha 5 \beta 1$ integrin was excluded from playing a role (63). Similar observations were made with KLK7-expressing SKOV3 cells in a 3D suspension microenvironment, where overexpression of KLK7 led to increased levels of $\alpha 5 \beta 1$ and $\beta 1$ integrin in spheroids, resulting in enhanced adhesion to fibronectin and vitronectin, potentially promoting homing (64). This phenomenon was inhibited with an antibody directed against integrin $\beta 1$ (64). Four members of the KLK family (KLK5-8), are overexpressed and up-regulated in tumor samples of serous EOC in comparison to normal ovarian tissue at the RNA level (Figure 2). These data corroborate previous data indicating that KLKs can serve as important biomarkers in ovarian carcinoma (54). Regarding their role in therapeutic intervention in metastasis of ovarian cancer, more target-validation experiments are necessary, for example, in models of patient-derived EOC growth in immune-compromised mice. In this context, it is important to note that the KLK system is likely to share the same problems from the perspective of target identification as all tumor-associated proteolytic systems, namely the possible redundancy of as well as the multiple physiological functions of its members.

The ECM consists of ground substance and fibers. The ground substance is composed of proteoglycans, multiadhesive glycoproteins and glycosaminoglycans, the fibers consist of collagen and elastin (65). The ECM is essential for tissue integrity, mediating processes such as proliferation, migration, and differentiation and functioning as a reservoir for sequestered cytokines and growth factors. In ovarian cancer, components of the ECM trigger proliferation, invasion, dissemination, and spheroid formation in the early steps of metastasis. Cleavage of vitronectin and fibronectin by MMP2 were pinpointed as early steps of ovarian carcinoma metastasis (66). In the later steps of metastasis, ECM components mediate homing by attachment of cancer cells to peritoneal cells, as is outlined later.

Hyaluronic acid (HA) is an important large proteoglycan component of the ECM, playing a dual role in metastasisrelated processes such as dissemination by attenuating cellcell interactions on one hand and facilitating homing due to its cell-cell adhesion-promoting function on the other hand (67). These processes are dependent on HA size, HA-binding proteins and cell-surface receptors for HA (67). High levels of HA were found to correlate with poor prognosis in ovarian carcinoma (68). The principal surface receptor for HA is the adhesion molecule CD44 (69). Binding of HA to CD44 promotes ovarian cancer cell migration via human epidermal growth factor receptor 2 (HER2) activation and nuclear translocation of $\beta$-catenin, as well as cell division cycle 42 (CDC42) and extracellular signal-regulated kinase (ERK) signaling (70). On the other hand, interaction between HA and CD44 can mediate adhesion of ovarian cancer cells to peritoneal cells, at least in part (71). CD44 is expressed by ovarian cancer cells as well as peritoneal cells and can thus facilitate cross-linking (adhesion) of CD44-binding proteins HA and versican (72). Involvement of CD44 in the process of peritoneal implantation was documented by the finding that antibody-mediated inhibition of CD44 inhibited implantation of tumor cells in ovarian cancer xenografts in nude mice (73). Versican is increased in ovarian carcinoma and its expression levels have been correlated with poor patient outcome (74). Metastasis-promoting communication between ovarian cancer cells and mesothelial cells were shown with conditioned media (CM) from both cell types. For example, CM from primary human mesothelial cells chemotactically induced migration of $\mathrm{OvCa}$ cell line through 


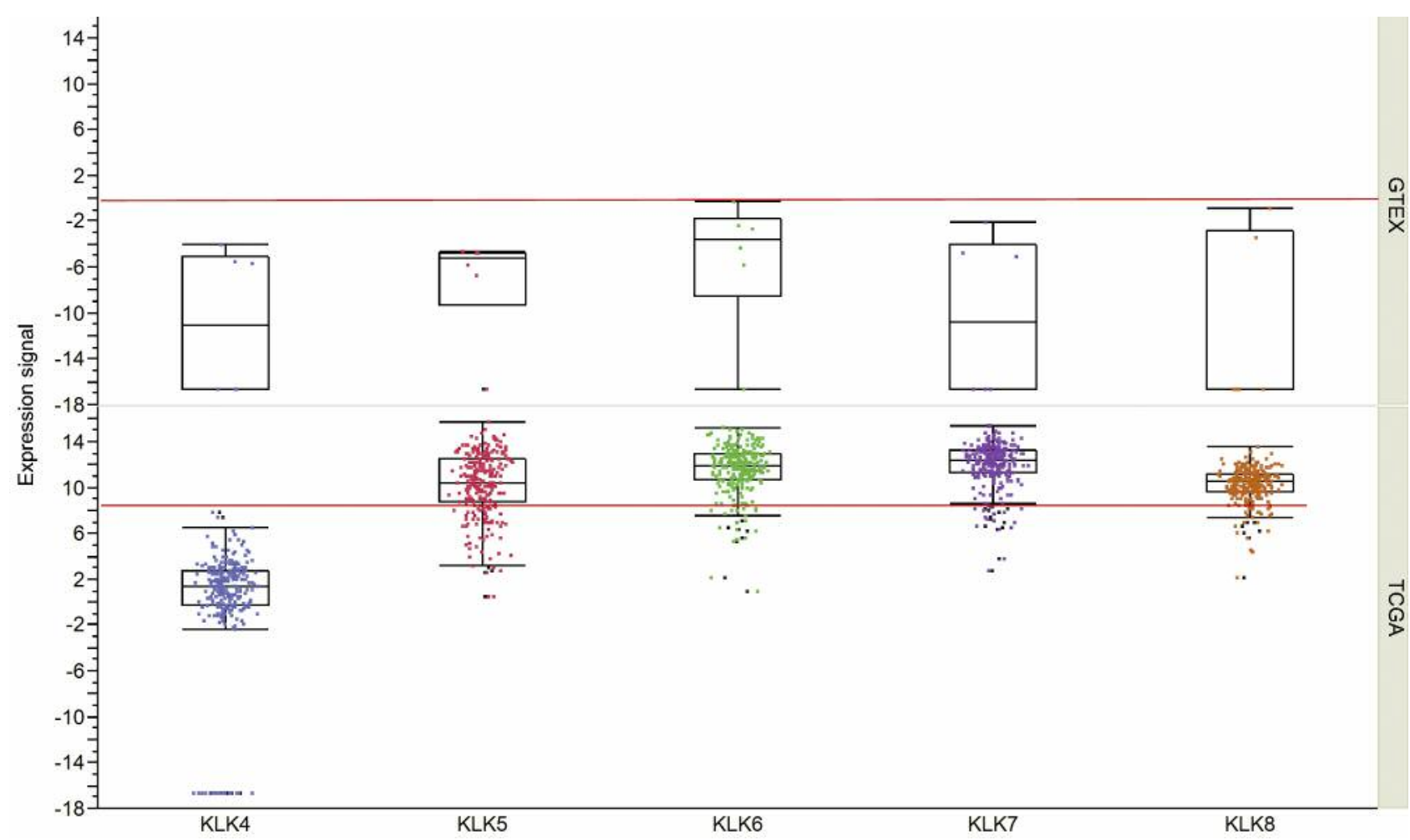

Figure 2. Expression of selected kallikrein (KLK) family members in normal ovarian tissues and ovarian tumors as measured by RNA sequencing of normal ovarian tissues ( $n=6)$ [Broad Genotype-Tissue Expression project (GTEX) atlas] (upper panel) and ovarian serous cystadenocarcinoma ( $n=216$ ) from The Cancer Genome Atlas (TCGA) (lower panel). Expression values are given as log2 reads per kilobase per million mapped reads (RPKM) values for GTEX and as normalized read counts for the TCGA data (157). Expression values are therefore not directly comparable. The two red lines indicate low and high expression in the two datasets. Thresholds were set to an RPKM $\geq 1$ for GTEX and a read count $\geq 100$ for TCGA. Expression data are shown as box plots, where the black line represents the median, and the black rectangles show the upper and lower 25\% quartile. Therefore, $50 \%$ of all data points are included in the black rectangle. All other data points, except for outliers, are located between the upper and lower whiskers.

gelatin-coated Boyden chambers (75), and other experiments have shown that peritoneal cells can promote $\mathrm{OvCa}$ cell/peritoneal cell adhesion (76). These findings indicate reciprocal interactions between both cell types mediated by secreted factors. Further investigations have implicated fibronectin in formation and adhesion to peritoneal cells of OvCa spheroids $(77,78)$. These observations are compatible with earlier findings of detection of covalently-linked fibrinfibronectin compounds in the stroma surrounding ovarian cancer metastases and in corresponding ascites (79).

Mesothelial cell-secreted fibronectin was identified and investigated in more detail (78). It was shown that human mesothelial cells secrete fibronectin in the presence of $\mathrm{OvCa}$ cells in organotypic 3D cultures and that fibronectin was consistently overexpressed in the stroma of 108 omental metastases. Blocking fibronectin expression in vitro or in vivo either genetically in a fibronectin floxed mouse model or via RNAi resulted in decreased proliferation, invasion, and adhesion of OvCa cells. Overexpression of fibronectin was based on activation of the TGF $\beta$ receptor/ Ras-related $\mathrm{C} 3$ botulinum toxin substrate (RAC1)/SMAD signaling pathway in mesothelial cells by OvCa cell-secreted TGF $\beta$ (78). It is likely that $\alpha 5$ and $\beta 1$ integrin subunits are involved in interaction with fibronectin, since monoclonal antibodies (mAbs) against these subunits can block adhesion of tumor cells to peritoneal cells (78). Although several isoforms of fibronectin have been identified (80), it is important to note that the fibronectin-related phenomena described in this review are not assigned to defined isoforms. A critical issue regarding the therapeutic value of components of the ECM with respect to their potential for therapeutic intervention with ovarian cancer metastasis is their ubiquitous expression in normal tissues, resulting in a lack of tumor specificity, and their dual role in promoting dissemination as well as adhesion in a context-dependent manner. 
Transmembrane molecules (integrins, MUC16, L1CAM, c$M E T)$. Integrins, MUC16, L1CAM and c-MET are involved in several steps of transcoelomic metastasis of EOC. As we describe in the following, MUC16 and integrins are mediators of dissemination and homing, whereas L1CAM and c-MET are primarily involved in dissemination and growth.

Integrins: Integrins are important mediators of invasion, dissemination, spheroid formation, and homing, as well as regulators of the plasminogenolytic system in ovarian carcinoma metastasis (81). They are cell-surface glycoprotein receptors composed of non-covalently associated $\alpha$ and $\beta$ subunits (82). A unique set of ligands can bind to the assembled heterodimers and mediate signaling through their cytoplasmic domains (82). Components of the ECM such as fibronectin, laminin, collagen and vitronectin are ligands for integrins (82). The general role of integrins in cell migration and invasion is well documented (83). Binding of plasminogen activator inhibitor 1 (PAI-1) to uPAR enables interaction of this complex with adjacent ECM integrins, promoting their internalization, thereby reducing the adhesive strength of cells for their substratum, resulting in cell detachment (84).

The integrin subunit $\beta 1$ can heterodimerize with many different $\alpha$ subunits creating entities which have essential functions in ovarian cancer metastasis (81). This subunit is able to bind to laminin, fibronectin and type IV collagen, is induced by CXCL12-chemokine receptor 4 (CXCR4) interaction, and can mediate invasiveness of ovarian carcinoma cells by inducing MMP2 and MMP9 expression $(81,82)$. An anti- $\beta 1$ function-blocking antibody can inhibit spheroid formation, whereas an antibody inducing clustering of $\beta 1$ promotes spheroid formation (70). The function of integrin $\beta 1$ in promoting homing was shown through inhibition of binding of ovarian cancer cells to peritoneal mesothelium in vitro with another anti- $\beta 1$ antibody (85). Several studies have focused on the role of $\alpha 5 \beta 1$, which is expressed in $40 \%$ of patients with advanced ovarian carcinoma and is involved in dissemination of ovarian cancer $(85,86)$. For example, interaction between $\alpha 5 \beta 1$ and fibronectin was shown to be involved in formation of spheroids (85). Loss of E-cadherin leads to up-regulation of $\alpha 5 \beta 1$, facilitating the adhesion of ovarian carcinoma to secondary sites in the peritoneum (87). A chimeric $\alpha 5 \beta 1 \mathrm{mAb}$ (Volocixumab) which blocks the interaction between $\alpha 5 \beta 1$ integrin and fibronectin is currently being clinically evaluated in patients with platinum-resistant advanced epithelial ovarian carcinoma or primary peritoneal cancer (88).

The following studies have shown that other integrins play role in ovarian cancer. Vascular cell adhesion molecule 1 (VCAM1) is a homing-related molecule which is expressed on mesothelial cells and interacts with $\alpha 4 \beta 1$ on ovarian cancer cells (89). Function-blocking antibodies directed against VCAM1 and the $\alpha 4$ - or $\beta 1$ subunits of $\alpha 4 \beta 1$ integrin, respectively, abolished dissemination and colonization in an ovarian cancer xenograft model (89). Expression of $\alpha 6 \beta 1$ integrin in EOC regulates ECM degradation via the plasminogen activation cascade (90). The pathophysiological context was underlined by the demonstration that ascitic fluid can induce up-regulation of $\alpha 6 \beta 1$ and uPAR, with subsequent enhancement of proliferation, invasiveness, and adhesion of ovarian cancer cell lines to peritoneal cells (90). Integrins $\alpha 6 \beta 1, \alpha 2 \beta 1$ and $\alpha 3 \beta 1$ have been implicated in spheroid adhesion of ovarian cancer cells to peritoneal cells through binding to laminin and type IV collagen, respectively (86). Taken together, due to the lack of tumor-specific expression, their involvement in a plethora of normal physiological processes, and their inherent functional redundancy, targeting of integrins for inhibition of ovarian cancer metastasis remains an unresolved issue with respect to its therapeutic benefit in treatment or prevention of EOC metastases.

MUC16: MUC16 (also known as marker CA125) is a heavily $O$ - and $\mathrm{N}$-glycosylated transmembrane protein, which is overexpressed in $85 \%$ of serous EOCs (91). MUC16 is a large protein (3-5 million $\mathrm{Da}$ ) with a tandem repeat region of 60 repeats consisting of 156 amino acids each, sandwiched beween $N$ - and $C$-terminal domains (91). MUC16 displays a discontinuous peptide epitope, CA125, which is a marker for monitoring expression and recurrence of EOC by quantitating serum levels of CA125 in patient-derived material (92-94). As derived from public databases and as shown in Figure 3, MUC16 is expressed and up-regulated in ovarian tumor tissue in comparison to normal ovarian tissue at the RNA level. As outlined in the following, MUC16 is involved in proliferation, dissemination, and homing of ovarian carcinoma cells. The cytoplasmic domain of MUC16 can associate with SRC-family kinases. These interactions can lead to proliferation, migration and dissemination of ovarian cancer cells (91). Secreted MUC16 confers an immune-protective effect by interacting with Siglec 9, a receptor found on natural killer cells which inhibits the in response (95). A possible relationship between MUC16 and metastasis was indicated by decrease of MMP2 after its knock-down, followed by inhibition of invasion (96). It was shown that binding of MUC16-derived N-glycan to glycosylphosphatidyl-inositol anchored mesothelin (MLN) might be the initial contact between ovarian cancer cells and the peritoneal surface in the context of the homing process $(97,98)$. Shedding of MUC16 by MT-MMP1 reduced binding to mesothelial cells and intact peritoneal implants (99). Binding of MUC-16 to recombinant Fc-tagged MLN indicated highaffinity interaction $(\mathrm{Kd}=5-10 \mathrm{nM})(97,98)$. Importantly, MUC16-MLN interaction even occurred in the presence of ascites, which normally has a high level of CA125 in patients with EOC; and MLN-specific antibodies blocked the adhesion of ovarian cancer cells to mesothelial cells $(97,98)$. Since tumor cells express both MLN and MUC16, whereas the mesothelium expresses MLN but not MUC16, tumor cell 


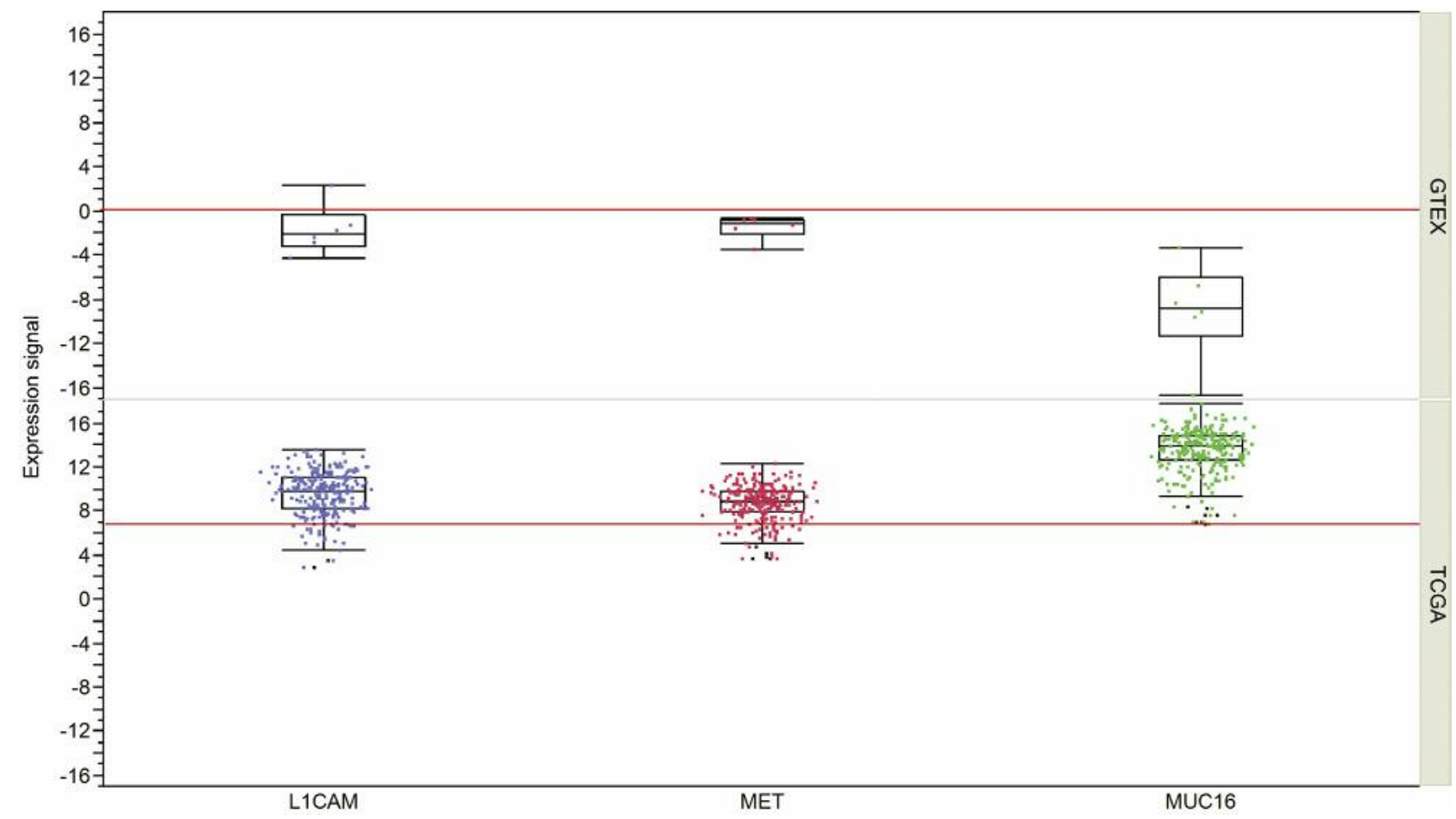

Figure 3. Expression of L1 cell adhesion molecule (L1CAM), transmembrane tyrosine kinase c-MET proto-oncogene product (MET) and mucin 16 (MUC16) in normal ovarian tissues and ovarian tumors. Expression, as measured by RNA sequencing of normal ovarian tissues ( $n=6)$ [Broad Genotype-Tissue Expression project (GTEX) atlas] and ovarian serous cystadenocarcinoma (n=216) from The Cancer Genome Atlas (TCGA) are shown in the upper and lower panel, respectively. For GTEX, expression values are given as log2 reads per kilobase per million mapped reads (RPKM) values and as normalized read counts for the TCGA data (157). Expression levels are, therefore, not directly comparable. The two red lines indicate low and high expression in the two datasets. Thresholds have been set to an RPKM $\geq 1$ for GTEX and Read Count $\geq 100$ for TCGA. Expression data are shown as box plots where the black line represents the median and the black rectangles show the upper and lower 25\% quartile. Therefore, $50 \%$ of all data points are included in the black rectangle. All other data points, except for outliers are located between the upper and lower whiskers.

aggregate formation as well as tumor cell/mesothelial cell interactions can be explained by MUC16-MLN complex formation (98). Current therapeutic efforts focusing on MUC16 as a target are based on an antibody conjugate (DMU5754A) which is composed of a mAb directed against MUC16 and covalently-linked monomethyl-auristatin E (MMAE) as a cytotoxic component $(94,100,101)$. Site-specific coupling has improved the therapeutic index of this conjugate (102). DMU5754A is currently in clinical evaluation in platinumresistant ovarian carcinoma patients. Despite expression of MUC16 in mucinous epithelia of the respiratory and female genital tract, as well as in salivary glands and nasopharynx (103), toxicity was low. One complete response and reduction of tumor mass in five patients out of a cohort of 20 patients was observed (104), indicating potential for clinical efficacy of DMU5754A. As a bottom-line, MUC16 appears to be a promising target for treatment of ovarian cancer metastases.

L1CAM: L1CAM is an important mediator of migration, invasion and proliferation of ovarian carcinoma cells, as well as growth of disseminated cells, as outlined in the following. L1CAM is a neuronal adhesion molecule consisting of six Iglike domains and five fibronectin-like domains in the extracellular domain, a transmembrane domain and a cytoplasmic domain with five potential phosphoserine residues which can interact with components of the cytoskeleton, second messenger pathways, kinases, and the nuclear factor-kB (NF-kB) signaling pathway $(105,106)$. In normal ovarian epithelial cells and EOC cells, L1CAM exhibits several differential functions (107). In normal ovarian epithelial cells, it supports cell-cell adhesion, enhances apoptosis and has no effect on proliferation, whereas in EOC cell lines, L1CAM inhibits cell-cell adhesion and apoptosis. The switch in function in ovarian cancer cells is due to cleavage of the extracellular domain by a disintegrin and metalloprotease domain (ADAM) proteases resulting in binding to integrins via its arginine-glycineaspartic acid motif in the sixth Ig-domain (108). L1CAMintegrin binding induces production and release of interleukin 
$1 \beta$ (IL1 $\beta$ ) which binds to the the IL1 receptor, resulting in activation of NFkB signaling. Soluble L1CAM can bind to integrins in an autocrine/paracrine fashion and thereby promote cell migration (108). It was shown that invasion of EOC cell lines is dependent on ERK1/2 and PI3K signaling, as well as on expression of MMP2 and MMP9 $(108,109)$. The proliferation-mediating effect of L1CAM was demonstrated with mAbs directed against L1CAM (110). L1CAM is expressed and up-regulated in ovarian tumor tissues in comparison to normal ovarian tissues at the RNA level (Figure 3). Based on in vitro and patient data, it was demonstrated that L1CAM and its soluble version can induce IL1 $\beta$ (111). A clinical study based on quantitation of soluble L1CAM in ascites from 232 patients with serous EOC revealed soluble L1CAM as a marker for decreased progression-free survival and chemoresistance, as well as abundant expression of IL1 $\beta$ in ascitic fluid (112). An immunohistochemistry-based study reported that L1CAM expression is a marker for unfavorable prognosis in EOC (113). L1CAM expression in the corresponding tumors correlated with a highly invasive phenotype, limited resectability, and metastatic spread. The role of L1CAM in ovarian cancer metastasis was underlined by two in vivo models $(109,110)$. Treatment of nude mice xenografted intraperitoneally with SKOV3 ovarian cancer cells with a mAb directed against L1CAM led to inhibition intraperitoneal tumor growth and dissemination (110). In the second model, knock-down of L1CAM in SKOV3 cells resulted in decreased experimental metastasis to the lungs (109).

Treatment with mAbs or immunoconjugates directed against L1CAM are emerging as options for therapy of EOC and should be further evaluated in preclinical ovarian cancerrelated models. Involvement of L1CAM in proliferation, migration, invasion and growth of EOC cells support ranking L1CAM as a high priority target for treatment of metastases of EOC. One of the critical issues for treatment of ovarian cancer dissemination with antibody-related moieties directed against L1CAM is the requirement for homogeneity of expression of the antigen on cells of the corresponding tumors in the absence of bystander effects of this kind of therapy. Due to expression of L1CAM on cells of the peripheral nervous system and in the kidney, the side-effect profile of the corresponding agents has to be assessed properly in species which cross-react with the antibody moiety of the agent $(105,114)$.

Transmembrane tyrosine kinase c-MET: The role of receptor transmembrane tyrosine kinase c-MET mediated signaling in the pathogenesis of several types of cancer is well documented $(115,116)$. As shown in the following, cMET acts as a mediator of dissemination and growth of ovarian carcinoma cells. c-MET activates an invasive growth program via rat sarcoma (RAS), mitogen-activated protein kinase (MAPK), phosphatidylinositol-3-kinase (PI3K), signal transducer and activator of transcription (STAT), $\beta$-catenin, or NOTCH pathways $(115,116)$. Cross-talk between transmembrane kinases c-MET, receptor d'origine nantais (RON), and epidermal growth factor receptor has been shown to increase invasiveness of ovarian cancer cells through secretion of MMP9 $(117,118)$. c-MET ligand HGF was originally identified as scatter factor due to its migrationpromoting activity (119) and is secreted into the ascites of patients with ovarian carcinoma as a stimulator of ovarian cancer cell migration (117). In addition to its function as a promoter of dissemination, a metastasis-related function of cMET in the growth of metastases was identified, since c-MET leads to promotion of angiogenesis (120). In 30\% of ovarian carcinomas, c-MET is overexpressed 3- to 50-fold at the protein level in comparison to normal matching tissue (121). The Cancer Genome Atlas (TCGA)-related data also confirmed up-regulation of $c-M E T$ in ovarian tumor tissues in comparison to normal ovarian tissue at the RNA level (Figure 3). In patients with ovarian carcinoma, overexpression of c-MET protein is associated with a poor prognosis and a lower survival rate in comparison to those with low expression of c-MET (17 months vs. 32 months) (122). In an in vivo ovarian cancer xenograft model, as a proof-of-concept experiment, RNAi directed against c-MET resulted in $85 \%$ inhibition of the number of metastatic nodules, tumor weight and ascites (122).

c-MET expression is up-regulated by metastasis associated in colon cancer 1 (MACC1) (123). This results in promotion of proliferation, invasion and HGF-induced scattering of colon cancer cells in vitro and in mouse models of colorectal cancer. MACC1 is a prognostic factor for CRC metastasis in patients (123). It was shown that MACC 1 also induces upregulation of $c-M E T$ in the OVCAR3 ovarian cancer cell line (123). Small interfering RNA directed against MACC-1 reduced expression of c-MET protein, migration, and invasion in this cell line (123). A putative MACC1-binding site was identified in the 3'untranslated region of $c$-MET.

Currently a number of mAbs, which inhibit activation of c-MET by interfering with binding of HGF or interfering with dimerization of c-MET as a prerequisite for activation, and small molecules that inhibit its tyrosine kinase activity by competition with ATP binding or due to allosteric mechanisms are under clinical evaluation in diverse cancerrelated indications (125). Among these compounds are selective small molecule c-MET inhibitors such as tivantinib (ARQ197) and PF04217903 as well as molecules with a broader spectrum of inhibition, such as crizotinib, cabozantinib (XL184) and foretinib (125).

Chemokines/chemokine receptors: The role of the interaction between G-protein-coupled chemokine receptors (GPCRs) and their respective ligands in the pathogenesis of ovarian cancer as well as dissemination, homing and growth of metastases are well documented (126). The CXCL12- 
CXCR4 axis is an example for this kind of interaction and plays an important role in dissemination of ovarian cancer. Originally this interaction was shown to be essential for the homing of hematopoietic stem cells to the bone marrow and compounds which abolish this interaction, such as Plerixafor (AMD3100), lead to mobilization of hematopoietic stem cells (127). Plerixafor has been approved for routine clinical use for this purpose.

In ovarian carcinoma, CXCR4 is expressed in tumor cells and CXCL12 is found in ascites (128). CXCL12 enhances ovarian cancer cell invasion through an $\alpha v \beta 6$ integrindependent mechanism with downstream effectors such as p38MAPK and PI3K/AKT resulting in up-regulation of uPA and MMP9 $(129,130)$. It was shown that $\beta 1$-integrin mediated NFKB signaling up-regulates CXCR4 in tumor cells when they encounter interstitial collagen-rich ECM in 3D type I collagen gels (130). AMD3100 and abrogation of CXCR4 by specific RNAi reduced intraperitoneal metastasis and almost completely abolished metastasis to the omentum in models of ovarian cancer metastasis $(129,130)$. Since CXCL12-CXCR4 interaction is a mediator of angiogenesis, an impact on growth of EOC metastases is probable (131). Since CXCL12-CXCR4 interaction drives proliferation, survival, invasion and growth of ovarian cancer cells, CXCL12 and CXCR4 are promising targets for antimetastatic treatment of ovarian cancer.

In the following, we describe three additional GPCRs and their ligands involved in dissemination of EOC. Lymphotactin receptor XC chemokine receptor 1 (XCR1), a GPCR expressed in ovarian cancer and not in normal ovarian tissue, was shown to mediate increased migration and proliferation of ovarian cancer cells by interactions with lymphotactins 1 and 2 (132). Interaction of peritoneal cellexpressed membrane-bound form of fractalkine receptor $\mathrm{C}$ X3-C motif ligand 1 (CX3CL1) with CX3C chemokine receptor 1 (CX3CR1) on ovarian tumor cells as a mediator of homing-related adhesion was demonstrated by impairment of adhesion with function blocking antibodies directed against CX3CL1 and also by its down-regulation by RNAi (133). The contribution of stromal cells to homing of disseminated ovarian cancer cells has also been investigated. As an example, the cytokine lymphotoxin, which induces CXCL11 on stromal cells and mediates its physiological effect by binding to CXCR3 expressed by ovarian cancer cells, was identified as an essential component of the homing process of disseminated ovarian cancer cells (134). The latter targets need further preclinical validation for ranking of their priority as therapeutic targets for treatment of ovarian cancer. Overall, CXCL12-CXCR4 interaction seems to be the best validated ligand-GPCR pair in the context of EOC dissemination and might be a candidate target pair for clinical evaluation.

Fatty acid synthase (FASN) and fatty-acid binding protein 4 (FABP4) as metabolism-related targets: FASN and FABP4 are involved in proliferation, migration, dissemination and homing, as well as growth of ovarian carcinoma cells, as outlined in the following. Current efforts regarding lipid metabolism as a therapeutic target for ovarian carcinoma have focused on de novo fatty acid synthesis via glycolysis and glutaminolysis in oncogene-transformed cells (135). Fatty acid synthase (FASN) promotes proliferation and EMT via transcriptional regulation of E-cadherin and $\mathrm{N}$ cadherin and its overexpression correlates with dissemination and peritoneal metastasis of ovarian cancer (136). In this context, it was shown that blockage of FASN induces ubiquitination and degradation of PI3K signaling proteins in ovarian cancer (137). The involvement of FASN in the generation of phospholipids involved in the formation of membrane microdomains that accommodate receptor tyrosine kinases, including HER1 and HER2, has also been demonstrated (138). Since fatty acid synthesis is a physiological process also important for non-transformed cells, the question remains whether a therapeutic window can be identified for inhibitors of this process. An important role of adipocytes for ovarian cancer metastasis was discovered recently $(121,122)$. It was shown that five cytokines, IL6, IL8, monocyte chemoattractant protein (MCP1), tissue inhibitor of metalloproteinase 1 (TIMP1) and adiponectin, all secreted by omental adipocytes, promoted migration, invasion and adhesion (homing) of SKOV3 ovarian cancer cells to sections of the human omentum. Co-culture experiments with adipocytes and ovarian cancer cells revealed transfer of fluorescently labeled lipids from adipocytes to tumor cells. Increased lipolysis in adipocytes and increased $\beta$-oxidation in cancer cells was observed. Fatty acids provided by adipocytes act as an energy source to promote tumor invasion and growth, as well as the growth of nodules (121). In addition, it was found that fatty acid-binding protein 4 (FABP4) was upregulated in omental metastases compared to primary ovarian tumors. FABP4 was detected in ovarian cancer cells at the adipocyte-tumor cell interface (121). FABP4 is a regulator of lipolysis and acts as a fatty-acid transporter (140). Blockage of FABP4 by small molecules resulted in drastically reduced lipid accumulation in the cancer cells and adipocyte-mediated invasion. In Fabp 4 knock-out mice, metastatic growth of ovarian cancer cells was impaired $(139,141)$. Taken together, these data show FABP4 merits further exploration as a therapeutic target for inhibition of ovarian cancer metastasis. It will be interesting to see whether fatty acid-FABP4 interaction can be disrupted with small molecules of high selectivity and potency, and whether inhibition of this interaction is more selective in terms of tumor specificity than inhibition of FASN.

Pro-angiogenic factors: Growth of metastatic nodules in the peritoneum is dependent on angiogenesis (31). Following the metastatic process, disseminated tumor cells in ascites 
fluid first interact with the innermost layer of the peritoneum, the mesothelium. After adherence to and penetration of the mesothelium and subsequent invasion of the submesothelial connective tissue, tumor cells are able to induce remodeling of the ECM and promote angiogenesis as a prerequisite for tumor cell proliferation and growth as nodules. Involvement of pathways based on signaling of vascular endothelial growth factor (VEGF), platelet-derived growth factor (PDGF), fibroblast growth factors (FGFs) and angiopoietins have been identified in this context (31). In preclinical models, it was shown that the omentum is a major site for growth and metastasis of intraperitoneal tumors (142). In addition to tumor cells, a subset of hypoxic CD105expressing mesothelial cells are possible sources of VEGF and FGFs, which can promote angiogenesis (142). Further preclinical models of ovarian cancer with involvement of the peritoneum have underlined the role of VEGF-mediated neovascularization and increased vascular permeability of blood vessels in the peritoneum, a prerequisite for ascites formation (143). A humanized mAb directed against VEGFA, bevacizumab, has been approved for the treatment of ovarian carcinoma (144). Bevacizumab increases the efficacy of chemotherapy in early treatment of ovarian cancer as well as in relapsed, platin-resistant disease. Many other anti-angiogenic agents are under clinical development in patients with ovarian cancer. Among the protein-based agents are aflibercept, a VEGF trap which binds to and neutralizes all isoforms of VEGF, as well as AMG-706, a peptibody which binds to angiopoietins 1 and 2 and neutralizes their function (145). Another category of angiogenesis-inhibiting compounds are small molecule tyrosine kinase inhibitors with varying patterns of specificity, targeting VEGFR1, -2, and -3, PDGFRs and FGFRs (31). Examples are drugs such as sorafenib, sunitinib, BIBF 1120 and pazopanib, which are all in clinical development in different cancer-related indications (31).

Other targets. Additional important targets involved in metastasis of ovarian carcinoma have been identified. A selection of these targets are summarized in the following without outlining experimental details. Interaction of cluster of differentiation (CD95 with its ligand CD95L results in apoptosis in many types of cells. However, in ovarian carcinoma, this interaction promotes tumor growth and invasion (146). RAB25, a small GTPase, is amplified and upregulated in many ovarian carcinomas and regulates motility, aggressiveness, apoptosis and autophagy (147). Expression of forkhead box M1 (FOXM1), a transcription factor, correlates with poor prognosis as assessed by immunohistochemistry in 158 patients with ovarian carcinoma (148). FOXM1 induces ovarian cancer cell proliferation and migration of HO-8910 ovarian cancer cells, as well as expression of MMP2, MMP9 and VEGFA (148).
Several micro RNAs (miRNAs) have been shown to modulate invasion and metastasis of ovarian cancer cells. miR-150 and miR-146 are highly expressed in omental lesions compared to primary tumors and are involved in promoting spheroid formation and metastasis (149). miR-124 inhibits migration and invasion of ovarian cancer cells by targeting sphingosine kinase 1 (150). miR-124 is downregulated in clinical ovarian carcinoma species in comparison to normal tissues and down-regulation correlates with the severity of metastasis (150). miR-22 inhibits cell migration and invasion of ovarian cancer cells and has been linked to progression of ovarian carcinoma to late stages without impact on cell viability and apoptosis (151).

\section{Concluding Remarks}

As outlined, transcoelomic dissemination of ovarian cancer cells involves distinct steps such as dissemination of tumor cells from the primary tumor, formation of multicellular aggregates (spheroids), survival in ascites and interactions with cells of the microenvironment. The latter comprise crosstalk with immune cells and platelets, components of the stroma such as fibroblasts, endothelial cells and peritoneumrelated cells such as mesenterial cells and adipocytes. Analysis of the functional contribution of distinct steps of metastasis, such as dissemination, homing and growth of disseminated tumor cells as nodules, has resulted in identification of several molecular targets for therapeutic intervention. We did not discuss approaches based on the mutational status of the EOC of patients such as inducing synthetic lethality with poly ADP ribose polymerase inhibitors in patients with BRCAl or -2 mutations which are being evaluated in several ongoing clinical studies $(152,153)$. This also holds true for other synthetic lethality-based approaches based on the genetics of the primary tumor $(154,155)$.

The targets discussed in this review are involved in several steps of the metastatic cascade. In addition to targets for chemo-therapeutic agents such as cisplatin and paclitaxel, VEGFA and germline mutated $B R C A 1 / 2$ are presently the only clinically validated molecular targets for treatment of ovarian carcinoma. Therefore, in addition to the approved agents bevacizumab and oliparib, other antibody-related agents or small molecule inhibitors inhibiting VEGF signaling (144) and mutated BRCA1/2 $(152,153)$ are promising agents for achieving clinical benefit. Targets such as proteases, components of the ECM and integrins seem to be less promising due to issues of involvement in many normal physiological processes, lack of tumor specificity or functional redundancy within the target class. Transmembrane targets such as MUC16, L1CAM, c-MET and CXCR4 are upregulated in EOC and have been validated in several preclinical EOC-related in vivo models. They are druggable with antibodyrelated or small molecules and corresponding agents are 
candidates for clinical development. Fatty and metabolismrelated FABP4 is a promising intracellular target, but it has to be shown that potent and selective low molecular compounds with a tolerable therapeutic window can be identified.

Overall, the link between metastasis and chemoresistance should be investigated in more detail to identify targets for beneficial therapy of metastasis of ovarian cancer. In addition, identification of ovarian cancer-specific metastasis-associated membrane antigens would foster approaches for therapy of ovarian cancer metastasis based on antibody-related or small molecules.

\section{Acknowledgements}

The Authors would like to thank Achim Krüger, Technical University of Munich for continuous discussion.

\section{References}

1 Thibault B, Castells $\mathrm{M}$ and Delord J-P: Ovarian cancer microenvironment. Cancer Metastasis Rev 33: 17-39, 2014.

2 Hennessy BT, Coleman RL and Markman M: Ovarian cancer. Lancet 374: 1371-1382, 2009.

3 Bast RC Jr., Hennessey B and Mills GB: The biology of ovarian cancer: new opportunities for translation. Nat Rev Cancer 9: 415-428, 2009.

4 Sasaki H, Sheng YL, Schneiderman D, Xiao CW, Kotsuji F and Tsang BK: Apoptosis and chemoresistance in human ovarian cancer: Is XIAP a determinant? Biol Signals Recept 9: 122-130, 2000.

5 Cheng JQ, Jiang X, Fraser M, Li M, Dan HC, Sun M and Tsang BK: Role of X-linked inhibitor of apoptosis protein in chemoresistance in ovarian cancer: possible involvement of the phosphoinosite-3 kinase/AKT pathway. Drug Resist Updat 5: 131-146, 2002

6 Castells M, Milhas D, Gandy C, Thibault B, Rafii A and Couderc B: Microenvironment mesenchymal cells protect ovarian cancer from apoptosis by inhibiting XIAP inactivation. Cell Death Dis 4: e887, 2013.

7 Choi YP, Sims HS, Gao MQ, Kang S and Cho NH: Molecular portraits of intratumoral heterogeneity in human ovarian cancer. Cancer Lett 307: 62-71, 2001.

8 Schwarz RF, Ng CK, Cooke SL, Newman S, Temple J, Piskorz AM, Gale D, Saval K, Murtaza M, Baldwin PJ, Rosenfeld N, Earl HM, Sala E, Jimenez-Linan M, Parkinson CA, Markowetz $\mathrm{F}$ and Brenton JD: Spatial and temporal heterogeneity in highgrade serous ovarian cancer: a phylogenetic analysis. PLoS Med 12: e1001789, 2015.

9 Latifi A, Luwor RB, Bilandzic M, Nazaretian S,Stenvers K, Pyman J, Zhu H, Thompson EW, Quinn MA, Findlay JK and Ahmed N: Cells from the ascites of ovarian cancer patients: molecular phenotype of chemoresistant ovarian tumors. PLoS One 7: e46858, 2012.

10 Cannnistra SA: Cancer of the ovary. N Engl J Med 351: 25192529, 2004.

11 Tavassoli FA and Devilee P: Tumors of the Breast and Female Genital Organs. P. Kleihues and L.Sobin (eds.). Lyon France, IARC Press, pp. 113-203, 2003.
12 Vang R, Shih I-M and Kurman RJ: Ovarian low-grade and high grade serous carcinoma: pathogenesis, clinicopathologic and molecular biologic features, and diagnostic problems. Adv Anat Path 16: 267-282, 2009.

13 Kurman RJ: Origin and molecular pathogenesis of ovarian highgrade serous carcinoma. Annal Oncol 24: S10, 16-21, 2013.

14 Schmeler KM and Gershenson DM: Low-grade serous ovarian cancer: a unique disease. Curr Oncol Rep 10: 519-523, 2008.

15 Auersperg N, Edelson MI, Mok SC, Johnson SW and Hamilton TC: The biology of ovarian cancer. Sem Oncol 25: 281-304, 1998.

16 Boger-Megiddo I and Weiss NS: Histologic subtypes and laterality of primary epithelial tumors. Gynecol Oncol 97: 8083,2005

17 Tan DS, Agarwal R and Kaye SB: Mechanisms of transcoelomic metastasis in ovarian cancer. Lancet Oncol 7: 925-934, 2006.

18 Lengyel E: Ovarian cancer development and metastases: Am J Pathol 177: 1053-1064, 2010.

19 Judson PL, Geller MA, Bliss RL, Boente MP, Downs LS Jr, Argenta PA and Carson LF: Preoperative detection of peripherally circulating cancer cells and its prognostic significance in ovarian cancer. Gynecol Oncol 91: 389-394, 2003.

20 Tarin D, Price JE, Kettlewell MG, Souter RG, Vass AC and Crossley B: Mechanisms of human tumor metastasis in patients with peritoneo-venous shunts. Cancer Res 44: 35843592,1984

21 Fidler IJ: The pathogenesis of human tumor metastasis: the 'seed and soil' hypothesis revisited. Nat Rev Cancer 3: 452-458, 2003

22 Pradeep S, Kim SW, Wu SY, Nishimura M, ChaluvallyRaghavan P, Miyake T, Pecot CV, Kim SY, Choi HY, Bischoff FZ, Mayer JA, Huang L, Nick AM, Hall CS, Rodriguez-Aquayo C, Zand B, Dalton HJ, Arumuqam T, Lee HJ, Han HD, Cho MS, Rupaimoole R, Manqala LS, Seghal V, Oh SC, Liu J, Lee JS, Coleman RL, Ram P, Lopez-Beresrein G, Fidler IJ and Sood AK: Hematogenous metastasis of ovarian cancer: rethinking mode of spread. Cancer Cell 26: 77-91, 2014.

23 Hibbs K, Skubitz KM, Pambuccian SE, Casey RC, Burleson KM, Oegama TR Jr, Thiele JJ, Grindle SM, Bliss RL and Skubitz AP: Differential gene expression in ovarian carcinoma: identification of potential biomarkers. Am J Pathol 165: 397414, 2004.

24 Adib TR, Henderson S, Perrett C, Hewitt D, Bourmpoulia D, Ledermann $\mathrm{J}$ and Boshoff $\mathrm{C}$ : Predicting biomarkers for ovarian cancer using gene-expression analysis. Br J Cancer 90: 686-692, 2004.

25 Bayani J, Brenton JD, Macgregor PF, Beheshti B, Albert M, Nallainathan D, Karaskova J, Rosen B, Murphy J, Laframboise S, Zanke B and Squire JA: Parallel analysis of sporadic ovarian carcinomas by spectral karyotyping, comparative genomic hybridization and expression microarrays. Cancer Res 62: 34663476, 2002.

26 Israeli O, Gotlieb WH, Friedman E, Korach J, Friedman E, Goldman B, Zeltzer A, Ben-Baruch G, Rienstein S and AvrimGoldring A: Genomic analyses of primary and metastatic serous epithelial cancer. Cancer Genet Cytogenetics 154: 16-21, 2004.

27 Khalique L, Ayahan A, Whittacker JC, Singh N, Jacobs IJ, Gayther SA and Ramus SJ: The clonal evolution of metastases from primary serous epithelial ovarian cancers. Int J Cancer 124: 1579-1586, 2009. 
28 Fishman A, Shalom-Paz E, Fejgin M, Gaber E, Altaras M and Amiel A: Comparing the genetic changes in the primary and secondary tumor sites of ovarian cancer using comparative genomic hybridization. Int J Gynecol Cancer 15: 261-266, 2005.

29 Davidson B, Trope CG and Reich R: The role of the tumor stroma in ovarian cancer. Front Oncol 4, 104, eCollection, 2014

30 Colvin EK: Tumor-associated macrophages contribute to tumor progression in ovarian cancer. Front Oncol 4, 137, eCollection, 2014.

31 Gavalas NG, Liontos M, Trachana SP, Bagratuni T, Arapinis C, Liacos C, Dimopoulos MA and Bamias A: Angiogenesis-related pathways in the pathogenesis of ovarian cancer. Int J Mol Sci 14: 15885-15890, 2013

32 Naora H and Montell DJ: Ovarian cancer metastasis: integrating insights from disparate model organisms. Nat Rev Cancer 5: 355-366, 2005.

33 Zhou XM, Zhang $\mathrm{H}$ and Han X: Role of epithelial to mesenchymal transitions in gynecological cancers: pathological and therapeutic perspectives. Tumor Biol 35: 9523-9530, 2014.

34 Yao D, Dai C and Pen S: Mechanisms of the mesenchymalepithelial transition and its relationship with metastatic tumor formation. Mol Cancer Res 9: 1608-1620, 2011.

35 Kipps E, Tan DS and Kaye SB: Meeting the challenge of ascites in ovarian cancer: new avenues for therapy and research. Nat Rev Cancer 13: 273-282, 2013.

36 Ahmed N and Stenvers KL: Getting to know ovarian cancer ascites: opportunities for targeted therapy-based translational research. Front Oncol 3: 256, 2013.

37 Pease JC, Brewer M and Tinauer JS: Spontaneous spheroid budding from monolayers: a potential contribution to ovarian cancer dissemination. Biol Open 1: 622-628, 2012.

38 Frankel A, Buckman R and Kerbel S: Abrogation of taxol-induced $\mathrm{G}_{2}-\mathrm{M}$ arrest and apoptosis in human ovarian cancer cells grown as multicellular tumor spheroids. Cancer Res 57: 2388-2393, 1997.

39 Nieman KM, Kenny HA, Penicka CV, Ladanyi A, BuellGutbrod R, Zillhardt MR, Romero IL, Carey MS, Mills GB, Hotamisligil GS, Yamada SD, Peter ME, Gwin K and Lengyel E: Adipocytes promote ovarian cancer metastasis and provide energy for rapid tumor growth. Nat Med 17: 1498-1503, 2011.

40 Hagemann T, Wilson J, Kulbe H, Li NF, Leinster DA, Charles $\mathrm{K}$, Klemm F, Pukrop $\mathrm{T}$, Binder $\mathrm{C}$ and Balkwill FR: Macrophages induce invasiveness of epithelial cancer cells via NF-kappa B and JNK. J Immunol 175: 1197-1205, 2005.

41 Hagemann T, Lawrence T, Mc Neish I, Charles KA, Kulbe H, Thompson RG, Robinson SC and Balkwill FR: "Re-educating" tumor-associated macrophages by targeting NF-kappa B. J Exp Med 205: 1261-1268, 2008.

42 Egan K, Crowley D, Smyth P, O'Toole S, Spillane C, Martin C, Gallagher M, Canney A, Norris L, Conlon M, MacEvoyL, Ffrench B, Stordal B, Keegan H, Finn S, McEneaney V, Laios A, Ducrée J, Dunne E, Smith L, Berndt M, Sheils O, Kenny D and O'Leary J: Platelet adhesion and degranulation induce prosurvival and pro-angiogenic signalling in ovarian cancer cells. PLoS One 6: e26125, 2011.

43 Labelle M, Begum S and Hynes RO: Direct signalling between platelets and cancer cells induces an epithelial-mesenchymallike transition and promotes metastasis. Cancer Cell 20: 576590, 2011.

44 Davis AN, Afshar-Kharghan V and Sood AK: Platelets effects on ovarian cancer. Sem Oncol 41: 378-384, 2014.
45 Nieuwland R, van der Post, Lok CA, Kenter G and Sturk A: Microparticles and exosomes in gynecological neoplasias. Sem Thromb Hemost 36: 925-929, 2010.

46 Beach A, Zhang HG, Ratajczak MZ and Kakar SS: Exosomes: an overview of biogenesis, composition and role in ovarian cancer. J Ovarian Res 7: 14, 2014.

47 Tang MK and Wong AS: Exosomes: emerging biomarkers and targets in ovarian cancer. Cancer Lett 367: 26-33, 2015.

48 Cho JA, Park H, Lim EH, Kim KH, Choi JS, Lee JH, Shin JW and Lee KW: Exosomes from ovarian cancer cells induce adipose tissue-derived mesenchymal stem cells to acquire the physical and functional characteristics of tumor-supporting myofibroblasts. Gynecol Oncol 132: 379-386, 2011.

49 Schmalfeldt B, Prechtel D, Härting K, Späthe K, Rutke S, Konik E, Fridman R, Berger U, Schmitt M. Kuhn W and Lengyel E: Increased expression of matrix metallproteinases (MMP)-2, MMP9 and the urokinase-type plasminogen activator is associated with progression from benign to advanced ovarian cancer. Clin Cancer Res 7: 2396-2404, 2001.

50 Cho A, Howell VM and Colvin EK: The extracellular matrix in epithelial ovarian cancer - a piece of a puzzle. Front Oncol 5: $245,2015$.

51 Overall CM and Kleifeld O: Tumor microenvironment - opinion: validating matrix metalloproteinases as drug targets and antitargets for cancer therapy. Nat Rev Cancer 6: 227-239, 2006.

52 Wilhelm O, Schmitt M, Höhl S, Senekowitsch R and Graeff H: Antisense inhibition of urokinase reduces spread of human ovarian cancer in mice. Clin Exp Metastasis 13: 296-302, 1995.

53 Wilhelm O, Weidle U, Höhl S, Rettenberger P and Graeff $\mathrm{H}$ : Recombinant soluble urokinase receptor acts as a scavenger for urokinase-type plasminogen activator (uPA). Inhibition of proliferation and invasion of human ovarian cancer cells. FEBS Lett 337: 131-134, 1994

54 Dong Y, Loessner D, Irving-Rodgers H, Obermair A, Nicklin JL and Clements JA: Metastasis of ovarian cancer is mediated by kallikrein related peptidases. Clin Exp Metastasis 31: 135-147, 2014.

55 Hibbs K, Skubitz KM, Pambuccian SE, Casey RC, Burleson KM, Oegema TR, Jr, Thiele JJ, Grindle SM, Bliss RL and Skubitz AP: Differential gene expression in ovarian carcinoma: identification of potential biomarkers. Am J Pathol 165: 397414, 2004.

56 Santin AD, Zhan F, Bellone S, Palmieri M, Cane S, Bignotti E, Anfossi S, Gokden M, Dunn D, Roman JJ, O'Brien TJ, Tian E, Cannon MJ, Shaughnessy J Jr and Pecorelli S: Gene expression profiles in primary ovarian serous papillary tumors and normal ovarian epithelium: identification of candidate molecular markers for ovarian cancer diagnosis and therapy. Int J Cancer 112: 14-25, 2004.

57 Dong Y, Kaushal A, Brattsand M. Nicklin J and Clements JA: Differential splicing of KLK5 and KLK7 in epithelial ovarian cancer produces novel variants with potential as cancer biomarkers. Clin Cancer Res 9: 1710-1720, 2003.

58 Tanimoto H, Underwood LJ, Shigemasa K, Pamley TH and O'Brien TJ: Increased expression of protease $\mathrm{M}$ in ovarian tumors. Tumour Biol 22: 11-18, 2001.

59 Underwood LJ, Tanimoto H, Wang Y, Shigemasa K, Pamley TH and O'Brien TJ: Cloning of tumor-associated differentially expressed gene-14, a novel serine protease overexpressed by ovarian carcinoma. Cancer Res 59: 4435-4439, 1999. 
60 Beaufort N, Debela M, Creutzburg S, Kellermann J, Bode W, Schmitt M, Picard D and Magdolen V: Interplay of human tissue kallikrein 4 (hK4) with the plasminogen activation system: hK4 regulates the structure and functions of the urokinase-type plasminogen activator receptor. Biol Chem 387: 217-222, 2006.

61 Shield K, Ackland ML, Ahmed N and Rice GE: Multicellular spheroids in ovarian cancer metastases: Biology and pathology. Gynecol Oncol 113: 143-148, 2009.

62 Bilandzic M and Stenvers KL: Assessment of ovarian cancer spheroid attachment and invasion of mesothelial cells in real time. J Vis Exp, 87, 2014.

63 Dong Y, Stephens C, Walpole C, Swedberg JE, Boyle GM, Parsons BG, McGuckin MA, Harris JM and Clements JA: Paclitaxel resistance and multicellular spheroid formation are induced by kallikrein-related peptidase 4 in serous ovarian cancer cells in ascites mimicking microenvironment. PLoS One 8: e57056, 2013.

64 Dong Y, Tan OL, Loessner D, Stephens C, Walpole C, Boyle GM, Parsons PG and Clements JA: Kallikrein-related peptidase 7 promotes multicellular aggregation via the alpha(5) beta(1) integrin pathway and paclitaxel chemoreistance in serous epithelial ovarian carcinoma. Cancer Res 70: 2624-2633, 2010.

65 Bonnans C, Chou J and Werb Z: Remodelling the extracellular matrix in development and disease. Nat Rev Mol Cell Biol 15: 786-801, 2014.

66 Kenny HA, Kaur S, Coussens LM and Lengyel E: The initial steps of ovarian cancer cell metastasis are mediated by MMP-2 cleavage of vitronectin and fibronectin. J Clin Invest 118: 13671379, 2008.

67 Toole BP: Hyaluronan: from extracellular glue to pericellular cue. Nat Rev Cancer 4: 528-539, 2004.

68 Antilla MA, Tammi RH, Syrjänen KJ, Saarikoski SV and Kosma VM: High levels of stromal hyaluronan predict poor disease outcome in epithelial ovarian cancer. Cancer Res 60: 150-155, 2000.

69 Aruffo A, Stamenkovic J, Melnick M, Underhill CB and Seed $\mathrm{B}$ : CD44 is the principal cell surface receptor for hyaluronate. Cell 61: 1303-1313, 1990.

70 Bourguignon LY, Peyrollier K, Gilad E and Brightman A: Hyaluronan-CD44 interaction with neural Wiskott-Aldrich syndrome protein (N-WASP) promotes actin polymerization and ErbB2 activation leading to beta-catenin nuclear translocation, transcriptional up-regulation, and cell migration in ovarian tumor cells. J Biol Chem 282: 1265-1280, 2007.

71 Gardner MJ, Catterall JB, Jones LM and Turner GA: Human ovarian tumor cells can bind hyaluronic acid via membrane CD44: a possible step in peritoneal metastasis. Clin Exp Metastasis 14: 325-334, 1996.

72 Voutilainen K, Antilla M, Silanpää S, Tammi R, Tammi M, Saarikoski S, Kosma VM: Versican in epithelial ovarian cancer: relation to hyaluronan, clinicopathologic factors and prognosis. Int J Cancer 107: 359-364, 2003.

73 Strobel T, Swanson L and Cannistra SA: In vivo inhibition of CD44 limits intra-abdominal spread of a human ovarian cancer xenograft in nude mice: novel role for CD44 in the process of peritoneal implantation. Cancer Res 57: 1228-1832, 1997.

74 Ghosh S, Albitar L, LeBaron R, Welch WR, Samimi G, Birrer MJ, Berkowitz RS and Mok SC: Up-regulation of stromal versican in advanced stage serous ovarian cancer. Gynecol Oncol 119: 114-120, 2010.
75 Rieppi M, Vergani V, Gatto C, Zanetta G, Allavena P, Taraboletti $\mathrm{G}$ and Giavazzi R: Mesothelial cells induce the motility of human ovarian carcinoma cells. Int J Cancer 80: 303-307, 1999.

76 Ksiazek K, Mikula-Pietrasik J, Korybalska K, Dworacki G, Jörres A and Witowski J: Senescent peritoneal mesothelial cells promote ovarian cancer cell adhesion: the role of oxidative stress-induced fibronectin. Am J Pathol 174: 1230-1240, 2009.

77 Zand L, Qiang F, Roskelley CD, Leung PC and Auersperg N: Differential effects of cellular fibronectin and plasma fibronectin on ovarian cancer cell adhesion, migration and invasion. In Vitro Cell Dev Biol Anim 39: 178-182, 2003.

78 Kenny HA, Chiang CY, White EA, Schryver EM, Habis M, Romero IL, Ladanyi A, Penicka CV, George J, Matin K, Montag A, Wroblewski K, Yamada SD, Mazar AP, Bowtell D and Lengyel E: Mesothelial cells promote early ovarian cancer metastasis through fibronectin secretion. J Clin Invest 124: 4614-4628, 2014.

79 Wilhelm O, Hafter R, Coppenrath E, Pflanz MA, Schmitt M, Babic R, Linke R, Gössner W and Graeff H: Fibrin-fibronectin compounds in human ovarian tumor ascites and their possible relation to tumor stroma. Cancer Res 48: 3507-3514, 1988.

80 White ES, Baralle FE and Munro AF: New insights into form and function of fibronectin splice variants. J Pathol 216: 1-14, 2008.

81 Sawada K, Ohyagi-Hara C, Kimura T and Morishige K: Integrin inhibitors as therapeutic agents for ovarian cancer. J Oncol 2012: 2012: 915140.

82 Hamburger DS and Calderwood DA: Integrin signaling at a glance. J Cell Sci 122: 159-163, 2009.

83 Hood JD and Cheresh DA: Role of integrins in cell invasion and migration. Nat Rev Cancer 2: 91-100, 2002.

84 Czekay RP and Loskutoff DJ: Unexpected role of plasminogen activator inhibitor 1 in cell adhesion and detachment. Exp Biol Med 229: 1090-1096, 2004.

85 Casey RC, Burleson KM, Skubitz KM, Pambuccian SE, Oegema TR Jr., Ruff LE and Skubitz AP: Beta-1 integrins regulate the formation and adhesion of ovarian carcinoma multicellular spheroids. Am J Pathol 159: 2071-2080, 2001.

86 Strobel T and Cannistra S: $\alpha 1$-integrins partly mediate binding of ovarian cancer cells to peritoneal mesothelium in vitro. Gynecol Oncol 73: 362-367, 1999.

87 Sawada K, Mitra AK, Radiabi AR, Bhaskar V, Kistner EO, Tretiakova M, Jagadeeswaran S, Montag A, Becker A, Kenny HA, Peter ME, Ramakrishnan V, Yamada SD and Lengyel E: Loss of E-cadherin promotes ovarian cancer metastasis via alpha5-integrin, which is a therapeutic target. Cancer Res 68 : 2329-2339, 2008.

88 Bell-McGuinn KM, Matthews CM, Ho SN, Barve M, Gilbert L, Penson RT, Lengyel E, Palaparthy R, Gilder K, Vassos A, McAuliffe W, Weymer S, Barton J and Schilder RJ: A Phase II, single-arm study of the anti- $\alpha 5 \beta 1$ antibody volociximab as monotherapy in patients with platinum-resistent advanced epithelial ovarian or primary peritoneal cancer. Gynecol Oncol 121: 273-279, 2011.

89 Slack-Davis JK, Atkins KA, Harrer C, Hershey ED and Conaway M: Vascular cell adhesion molecule-1 is a regulator of ovarian cancer peritoneal metastasis. Cancer Res 69: 1469-1476, 2009.

90 Ahmed N, Riley C, Oliva K, Rice G and Quinn M: Ascites induces modulation of alpha6betal integrin and urokinase 
plasminogen activator receptor expression and associated functions in ovarian carcinoma. Br J Cancer 92: 1475-1485, 2005.

91 Theriault, Pinard, Comamala M, Migneault M, Beaudin J, Matte I, Boivin M, Piché A and Rancourt C: MUC16 (CA125) regulates epithelial ovarian cancer cell growth, tumorigenesis and metastasis. Gynecol Oncol 121: 434-443, 2011.

92 Bast RC, Klug TL, St John E, Jenison E, Niloff JM, Lazarus H, Berkowitz RS, Leavitt T, Griffiths CT, Parker L, Zurawski VR Jr and Knapp RC: A radioimmunoassay using a monoclonal antibody to monitor the course of epithelial ovarian cancer. $\mathrm{N}$ Engl J Med 309: 883-887, 1983.

93 O'Brien TJ, Beard JB, Underwood LJ, Dennis RA, Santin AD and York L: The CA 125 gene: an extracellular superstructure dominated by repeat sequences. Tumor Biol 22: 348-366, 2001.

94 Felder M, Karpur A, Gonzalez-Bosquet J, Horibata S, Heintz J, Albrecht R, Fass L, Kaur J, Hu K, Shoijael H, Whelan RJ and Patankar MS: MUC16 (CA125): tumor biomarker to cancer therapy, a work in progress. Mol Cancer 13: 129, 2014.

95 Belisle JA, Horibata S, Jennifer GA, Petrie S, Kapur A, André S, Gabius HJ, Rancourt C, Connor J, Paulson JC and Patankar MS: Identification of Siglec 9 as the receptor for MUC16 on human NK cells, B cells and monocytes. Mol Cancer 9: 118, 2010.

96 Reinartz S, Failer S, Schuell T and Wagner U: CA125 (MUC16) gene silencing suppresses growth properties of ovarian and breast cancer cells. Eur J Cancer 48: 1558-1569, 2012.

97 Rump A, Morikawa Y, Tanaka M, Minami S, Umesaki N, Takeuchi M and Miyajima A: Binding of ovarian cancer antigen CA125/MUC16 to mesothelin mediates cell adhesion. J Biol Chem 279: 9190-9198, 2004.

98 Gubbels JA, Belisle J, Onda M, Rancourt C, Migneault M, Ho M, Bera TK, Connor J, Sathyanarayana BK, Lee B, Pastan I and Patankar MS: Mesothelin-MUC16 binding is a high affinity, Nglycan dependent interaction that facilitates peritoneal metastasis of ovarian tumors. Mol Cancer 5: 50, 2006.

99 Bruney L, Conley KC, Moss NM, Liu Y and Stack MS: membrane-type I matrix metalloproteinase-dependent ectodomain shedding of mucin 16/CA-125 on ovarian cancer cells modulates adhesion and invasion of peritoneal mesothelium. Biol Chem 395: 1221-1231, 2014.

100 Chen Y, Clark S, Wong T, Chen Y, Chen Y, Dennis MS, Luis E, Zhong F, Bheddah S, Koeppen H, Gogineni A, Ross S, Polakis $\mathrm{P}$ and Mallet W: Armed antibodies targeting the mucin repeasts of the ovarian cancer antigen, MUC16, are highly efficacious in animal tumor models. Cancer Res 67: 4924-4932, 2007.

101 Das S and Batra SK: Understanding the unique attributes of MUC16 (CA125): potential implications in targeted therapy. Cancer Res 75: 4669-4674, 2015.

102 Junutula JR, Raab H, Clark S, Bhakta S, Leipold DD, Simpson M, Tsai SP, Dennis MS, Lu Y, Meng YG, Ng C, Yang J, Lee CC, Duenas E, Gorrell J, Katta V, Kim A, McDorman K, Flagella K, Venook R, Ross S, Spencer SD, Lee Wong W, Lowman HB, Vandlen R, Sliwkowski MX, Scheller RH, Polakis P and Mallet W: Site-specific conjugation of a cytotoxic drug to an antibody improves the therapeutic index. Nat Biotechnol 26: 925-932, 2008.

103 Wang Y, Cheon DJ, Lu Z, Cunningham SL, Chen CM, Luo RZ, Xing D, Orsulic S, Bast RC Jr and Behringer RR: MUC16 expression during embryogenesis, in adult tissues, and ovarian cancer in the mouse. Differentiation 76: 1081-1092, 2008.
104 Thudium K, Bilic S, Leipold D, Mallet W, Kaur S, Meibohm B, Erickson H, Tibbitts J, Zhao $\mathrm{H}$ and Gupta M: American Association of Pharmaceutical Scientists National Biotechnology Short Course: Translational challenges in developing antibodydrug conjugates: May 24, 2012, San Diego, CA. MAbs 5: 5-12, 2013.

105 Weidle UH, Eggle D, Klostermann S: L1-CAM as a target for treatment of cancer with monoclonal antibodies. Anticancer Res 29: 4919-4931, 2009.

106 Colombo F and Meldolesi J: L1-CAM and N-CAM: from adhesive proteins to pharmacologic targets. Trends Pharmacol Sci 36: 769-781, 2015.

107 Zecchini S, Bianchi M, Colombo N, Fasani R, Goisis G, Casadio C, Viale G, Liu H, Herlyn M, Godwin AK, Nuciforo PG and Cavallaro U: The differential role of L1 in ovarian carcinoma and normal surface epithelium. Cancer Res 68: 11101118, 2008.

108 Kiefel H, Bondong S, Hazin J, Ridinger J, Schirmer U, Riedle $S$ and Altevogt P: L1CAM: a major driver for tumor cell invasion and motility. Cell Adh Migr 6: 374-384, 2012.

109 Weinspach D, Seubert B, Schaten S, Honert K, Sebens S, Altevogt P and Krüger A: Role of L1 cell adhesion molecule (L1CAM) in the metastatic cascade: promotion of dissemination, colonization, and metastatic growth. Clin Exp Metastasis 31: 87$100,2013$.

110 Arlt MJ, Novak-Hofer I, Gast D, Gschwend V, Moldenhauer G, Grünberg J, Honer M, Schubiger PA, Altevogt P and Krüger A: Efficient inhibition of intra-peritoneal tumor cell growth and dissemination of human ovarian carcinoma cells in nude mice by anti-L1-cell adhesion molecule monoclonal antibody treatment. Cancer Res 66: 936-943, 2006.

111 Bondong S, Kiefel H, Hielscher T, Zeimet AG, Zeillinger R, Pils D, Schuster E, Castillo-Tong DC, Cadron I, Vergote I, Braicu I, Sehouli J, Mahner S, Fogel M and Altevogt P: Prognostic significance of L1CAM in ovarian cancer and its role in constitutive NF-kB activation. Annal Oncol 23: 1795-1802, 2012.

112 Fogel M, Gutwein P, Mechtersheimer S, Riedle S, Stoeck A, Smirnov A, Edler L, Ben-Arie A, Huszar M and Altevogt P: L1 expression as a predictor of progression and survival in patients with uterine and ovarian carcinomas. Lancet 362: 869-875, 2003.

113 Daponte A, Kostopoulou E, Kollia P, Papamichali R, Vanakara P, Hadjichristodoulou C, Nakou M, Samara S, Koukoulis G and Messinis E: L1 (CAM) (CD171) in ovarian serous neoplasms. Eur J Gynecol Oncol 29: 26-30, 2008.

114 Debiec H, Christensen EI and Ronco PM: The cell adhesion molecule L1 is developmentally regulated in the renal epithelium and is involved in kidney branching morphogenesis. J Cell Biol 143: 2067-2079, 1998.

115 Gherardi E, Birchmeier W and Vande Woude G: Targeting MET in cancer: rationale and progress. Nat Rev Cancer 12: 89-103, 2012.

116 Birchmeier C, Birchmeier W, Gherardi E and Vande Woude G: Met, metastasis, motility and more. Nat Rev Mol Cell Biol 4: 915-925, 2003.

117 Zhou HY, Pon YL and Wong AS: Synergistic effects of epidermal growth factor receptor and hepatocyte growth factor on human ovarian cancer cell invasion and migration: role of extracellular signal-regulated kinase $1 / 2$ and p38mitogenactivated protein kinase. Endocrinology 148: 5195-5208, 2007. 
118 Mhawech-Fauceglia P, Afkhami M and Pejovic T: MET/HGF signalling pathway in ovarian carcinoma: clinical implications and future direction. Patholog Res Int 2012: 9600327, 2012.

119 Stoker M, Gherardi E, Perryman M and Gray J: Scatter factor is a fibroblast-derived modulator of epithelial cell mobility. Nature 327: 239-242, 1987.

120 You WK and McDonald DM: The hepatocyte growth factor/cMET signaling pathway as a therapeutic target to inhibit angiogenesis. BMB Reports 41: 833-839, 2008.

121 DiRenzo MF, Olivero M and Katsarosetal D: Overexpression of the MET/HGF receptor in ovarian cancer. Int J Cancer 58: 658$662,1994$.

122 Sawada K, Radjabi AR, Shinomiya N, Kistner E, Kenny H, Becker AR, Turkylmaz MA, Salgia R, Yamada SD, Vande Woude GF, Tretiakowa M and Lengyel E: c-Met overexpression is a prognostic factor in ovarian cancer and an effective target for inhibition of peritoneal dissemination and invasion. Cancer Res 67: 1670-1679, 2007.

123 Stein U, Walther W, Arlt F, Schwabe H, Smith J, Fichtner I, Birchmeier W and Schlag PM: MACC1, a newly identified key regulator of HGF-MET signalling, predicts colon cancer metastasis. Nat Med 15: 59-67, 2009.

124 Sheng XJ, Li Z, Sun M, Wang ZH, Zhou DM, Li JQ, Zhao Q, Sun XF and Liu QC: MACC1 induces metastasis in ovarian carcinoma by upregulating hepatocyte growth factor receptor cMET. Oncol Lett 8: 891-897, 2014.

125 Garajova I, Giovannetti E, Biasco G and Peters GJ: c-MET as a target for personalized therapy. Transl Oncogenomics 7: S 13$31,2015$.

126 Muralidhar GG and Barbolina MV: Chemokine receptors in epithelial ovarian cancer. Int J Mol Sci 15: 361-376, 2013.

127 Bilgin YM and de Greef GE: Plerixafor for stem cell mobilization: the current status. Curr Opin Hematol 23: 67-71, 2016.

128 Scotton CJ, Wilson JL, Milliken D, Stamp G and Balkwill FR: Epithelial cell migration: a role for chemokine receptors? Cancer Res 61: 4961-4965, 2011.

129 Xue B, Wu W, Huang K, Xie T, Zhang H, Qi C, Ge J and Yu Y: Stromal cell-derived factor-1 (SDF-1) enhances cell invasion by av $\beta 6$ integrin-mediated signalling in ovarian cancer. Mol Cell Biochem 380: 177-184, 2013.

130 Barbolina MV, Kim M, Liu Y, Shepard J, Belmadani A, Miller RJ, Shea LD and Stack MS: Microenvironmental regulation of chemokine (C-X-C-motif) receptor 4 in ovarian carcinoma. Mol Cancer Res 8: 653-664, 2010.

131 Righi E, Kashiwagi S, Yuan J, Santosuosso M, Leblanc P, Ingraham R, Forbes B, Edelblute B, Collette B, Xing D, Kowalski M, Mingari MC, Vianello F, Birrer M, Orsulic S, Dranoff G and Poznansky MC: CXCL12/CXCR4 blockade induces multimodal antitumor effects that prolong survival in an immunocompetent mouse model of ovarian cancer. Cancer Res 71: 5522-5534, 2011.

132 Kim M, Rooper L, Xie J, Rayahin J, Burdette JE, KaidacsyBalla AA and Barbolina MV: The lymphotactin receptor is expressed in epithelial ovarian carcinoma and contributes to cell migration and proliferation. Mol Cancer Res 10: 1419-1429, 2012.

133 Kim M, Rooper L, Xie J, Kaidacsy-Balla AA and Barbolina MV: Fractaline receptor CX(3)CR1 is expressed in epithelial ovarian carcinoma cells and required for motility and adhesion to peritoneal mesothelial cells. Mol Cancer Res 10: 11-24, 2012.
134 Lan TS, Chung TK, Cheung TH, Chan LK, Cheung LW, Yim SF, Slu NS, Lo KW, Kulbe H, Balkwill FR and Kwong J: Cancer cell-derived lymphotoxin mediates reciprocal tumorstromal interactions in human ovarian cancer by inducing CXCL11 in fibroblasts. J Pathol 232: 43-56, 2014.

135 Levine AJ and Puizo-Kuter AM: The control of the metabolic switch in cancers by oncogenes and tumor suppressor genes. Science 330: 1340-1344, 2010.

136 Jiang L, Wang H, Li J, fang X, Pan H, Yuan X and Zhang P: Up-regulated FASN expression promotes transcoelomic metastasis of ovarian cancer cell through epithelialmesenchymal transition. Int J Mol Sci 15: 11539-11554, 2014.

137 Tomek K, Wagner R, Varga F, Singer CF, Karlic H and Grunt TW: Blockade of fatty acid synthase induces ubiquitination and degradation of phosphoinositide-3-kinase signalling proteins in ovarian cancer. Mol Cancer Res 9: 1767-1779, 2011.

138 Grunt TW, Wagner R, Grusch M, Berger W, Singer CF, Marian B, Zielinsky CC and Lupu R: Interaction between fatty acid synthase- and ErbB-systems in ovarian cancer cells. Biochem Biophys Res Comm 385: 454-459, 2009.

139 Nieman KM, Romero IL, Van Houten B and Lengyel E: Adipose tissue and adipocytes support tumorigenesis and metastasis. Biochim Biophys Acta 1831: 1533-1541, 2013.

140 Furuhashi M, Tuncman G, Görgün CZ, Makowski L, Atsumi G, Vaillancourt E, Kono K, Bahaev VR, Fazio S, Linton MF, Sulsky R, Robl JA, Parker RA and Hotamisligil GS: Treatment of diabetes and athersosclerosis by inhibiting fatty-acid-binding protein aP2. Nature 447: 959-965, 2007.

141 Hertzel AV, Hellberg K, Reynolds JM, Kruse AC, Juhlmann BE, Smith AJ, Sanders MA, Ohlendorf DH, Suttles J and Bernlohr DA: Identification and characterization of a small molecule inhibitor of fatty acid binding proteins. J Med Chem 52: 60246031, 2009.

142 Gerber SA, Rybalko VY, Bigelow CE, Lugade AA, Foster TH, Frelinger JG and Lord EM: Preferential attachment of peritoneal tumor metastases to omental immune aggregates and possible role of a unique vascular microenvironment in metastatic survival and growth. Am J Pathol 169: 1739-1752, 2006.

143 Nagy JA, Masse EM, Herzberg KT, Myers MS, Yeo KT, Yeo TK, Sioussat TM and Dvorak HF: Pathogenesis of ascites tumor growth: vascular permeability factor, vascular hyperperme-ability, and ascites fluid accumulation. Cancer Res 55: 360-368, 1995.

144 Ferrara N, Hillan KJ, Gerber HP and Novotny W: Discovery and development of bevacizumab, an anti-VEGF antibody for treating cancer. Nat Rev Drug Discov 3: 391-400, 2004.

145 Polverino A, Coxon A, Stames G, Diaz Z, DeMelfi T, Wang L, Bready J, Estrada J, Cattley R, Kaufman S, Chen D, Gan Y, Kumar G, Meyer J, Neervannan S, Alva G, Talvenheimo J, Montestruque S, Tasker A, Patel V, Radinski R and Kendall R: AMG 706, an oral, multikinase inhibitor that selectively targets vascular endothelial growth factor, platelet-derived growth factor, and kit receptors, potently inhibits angiogenesis and induces regression in tumor xenografts. Cancer Res 66: 8715$8721,2006$.

146 Chen L, Park SM, Tumanov AV, Hau A, Sawada K, Fein C, Turner JR, Fu YX, Romero IL, Lengyel E and Peter ME: CD95 promotes tumor growth. Nature 465: 492-496, 2010.

147 Chen KW, Lahad JP, Gray JW and Mills GB: Emerging role of RAB GTPases in cancer and human disease. Cancer Res 65: 2516-2519, 2005. 
148 Barger CJ, Zhang W, Hillman J, Stablewski AB, Higgins MJ, Vanswehyden BC, Odunski $\mathrm{K}$ and Karpf AR: Genetic determinants of FOXM1 overexpression in epithelial ovarian cancer and functional contribution to cell cycle progression. Oncotarget 6: 27613-27627, 2015.

149 Vang S, Wu HT, Fischer A, Miller DH, MacLaughlan S, Dougless E, Comisar L, Steinhoff M, Collins C, Smith PJ, Brard $\mathrm{L}$ and Brodsky AS: Identification of ovarian cancer metastatic miRNAs. PLoS One 8: e 58226, 2013.

150 Zhang H, Wang Q, Zhao Q and Di W: MiR-124 inhibits the migration and invasion of ovarian cancer cell by targeting SphK1. J Ovarian Cancer Res 6: 84, 2013.

151 Li J, Liang S, Yu H, Zhang J, Ma D and Lu X: An inhibitory effect of miR-22 on cell migration and invasion in ovarian cancer. Gynecol Oncol 119: 543-548, 2010.

152 Ratner ES, Sartorelli AC and Lin ZP: Poly (ADP-ribose) polymerase inhibitors: on the horizon of tailored and personalized therapies for epithelial ovarian cancer. Curr Opin Oncol 24: 564-571, 2012.

153 Konstantinopoulos PA, Ceccaldi R, Shapiro GI and D'Andreas AD: Homologous recombination deficiency: expoloiting the fundamental vulnerability of ovarian cancer. Cancer Discov 5: 1137-1154, 2015.
154 Etemadmoghadam W, Weir BA, Au-Yeung G, Alsop K, Mitchell G, George J, Australian Ovarian Cancer Study group, Davis S, DÁndrea AD, Simpson K, Hahn WC and Bowtell DD: Synthetic lethality between CCNE1 amplification and loss of BRCA1. Proc Natl Acad Sci USA 110: 19489-19494, 2013.

155 Bitler BG, Aird KM, Garipov A, Li H, Amatangelo M, Kossenkov AV, Schultz DC, Liu Q, Shih leM, Conejo-Garcia JR, Speicher DW and Zhang R: Synthetic lethality by targeting EZH2 methyltransferase activity in ARID1A-mutated cancers. Nat Med 21: 231-238, 2015.

156 Mortazavi A, Williams BA, McCue K, Schaeffer L and Wold B: Mapping and quantifiying mammalian transcriptomes by RNASeq. Nature Methods 5: 621-628, 2008.
Received May 18, 2016

Revised July 28, 2016

Accepted August 1, 2016 